\title{
Water balance of an earth fill built of organic clay
}

\author{
Emanuel Birle ${ }^{1 a}$, Dirk Heyer ${ }^{1}$ \\ ${ }^{1} T U$ München, Zentrum Geotechnik, 82284 München, Germany
}

\begin{abstract}
The paper presents investigations on the water balance of an earth fill built of organic clay in humid climate. As the organic soil used for the fill contains geogenetically elevated concentrations of arsenic, particular attention is paid on the seepage flow through the fill. The test fill is $5 \mathrm{~m}$ high, $30 \mathrm{~m}$ long and $25 \mathrm{~m}$ wide. The fill consists of the organic clay compacted at water contents wet and dry of Proctor Optimum covered by a drainage mat and a $60 \mathrm{~cm}$ thick top layer. For the determination of the water balance extensive measuring systems were installed. The seepage at the bottom measured so far was less than $2 \%$ of the precipitation. The interflow in the drainage mat above the compacted organic clay was of similar magnitude. The estimated evapotranspiration reached approx. $84 \%$ of the precipitation. According to these measurements the percolation is much lower than the percolation of many landfill covers in humid climates.
\end{abstract}

\section{Introduction}

In the area of the "Erdinger Moos", where the Munich Airport is located, the top soil consists of clays with organic content. These organic soils contain geogenetically elevated concentrations of arsenic. The organic top soils borrowed in the course of building activities are to be reused for noise and view protection embankments. Laboratory investigations were performed to investigate the compaction properties as well as the mechanical and hydraulic behaviour of the organic soils under compacted conditions. The results show that these organic soils can principally be used for such embankments. As the permeability of the soil is low, additional sealing layers are not necessary. For the detailed investigation of the hydro-mechanical behaviour and for the determination of seepage quantities a large scale, $5 \mathrm{~m}$ high, $30 \mathrm{~m}$ long and $25 \mathrm{~m}$ wide fill was constructed. For the measurement of the hydrology of the fill including seepage flow through the compacted organic soil extensive measuring systems were installed. The fill was constructed in autumn 2008. First results of the water balance of the fill were published at the fifth international conference on unsaturated soils 2010 in Barcelona [1] and at the GeoCongress 2012 [2]. Since then further measurements were taken and valuable information about the water balance could be gained.

In the following the design of the fill and the measuring instrumentation is briefly described. Thereafter, the results of the measurements are presented and the water flow within the fill is analysed.

\section{Soil properties}

According to DIN 18196, the soil used for the field test is a clay with organic content $(\mathrm{OH})$, with a liquid limit of $124 \%$ and a plastic limit of $44 \%$. The organic content determined by the ignition method lay between $25 \%$ and $30 \%$. For the determination of the compaction behaviour a Standard Proctor test was carried out. Other than in mineral soils no distinct Proctor Optimum could be determined. Furthermore, a dry density of approximately $0.8 \mathrm{~g} / \mathrm{cm}^{3}$ and a water content ranging between $55 \%$ und $75 \%$ was noted. The coefficient of permeability depends strongly on the compaction water content. For a water content of $55 \%$ a coefficient of permeability of $\mathrm{k}=5$. $10^{-8} \mathrm{~m} / \mathrm{s}$ and for a higher water content of $75 \%$ a lower coefficient of $\mathrm{k}=5 \cdot 10^{-9} \mathrm{~m} / \mathrm{s}$ was determined. The natural water content in the field varies, depending on climatic conditions, between $60 \%$ and $85 \%$.

The soil water retention curve (SWRC) was determined for compacted samples with an initial water content of $75 \%$ and a dry density of $0.8 \mathrm{~g} / \mathrm{cm}^{3}$. The low suction range up to $100 \mathrm{kPa}$ was investigated by means of tensiometers (matric suction). For the high suction range a chilled mirror dew-point hygrometer was used (total suction). Figure 1 shows the obtained drying and wetting curves. For the determination of the drying path, the samples were not previously saturated, the drying was rather started from the initial state after compaction. Starting from the initial state after compaction also a wetting path was determined. The main wetting path of the SWRC was investigated with samples previously dried from the initial state after compaction to a hygroscopic water content of approximately $3 \%$. To

\footnotetext{
a Corresponding author: e.birle@tum.de
} 
reduce the time required for the determination of the SWRC, several samples were prepared and dried to the desired water contents. Thereafter the matric suction was measured by tensiometers and the exact water content was determined by oven drying.

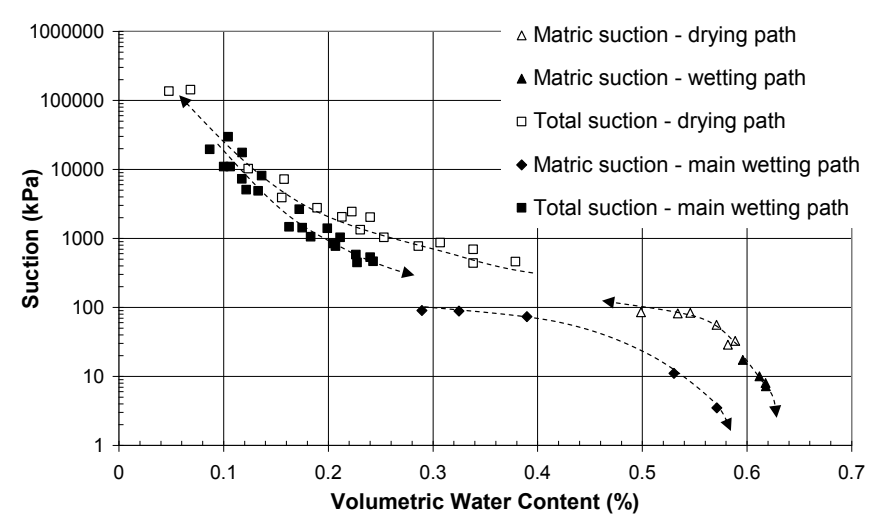

Figure 1. Soil water retention curve

\section{Design of the test fill}

The design of the fill is shown in Figure 2. The compacted organic soil is covered by a drainage mat and a $0.6 \mathrm{~m}$ thick top layer of organic clay. The fill is $5 \mathrm{~m}$ high, $30 \mathrm{~m}$ long and $25 \mathrm{~m}$ wide. As the hydraulic behaviour depends strongly on the compaction water content, it was decided to divide the fill in two parts. On the west side the soil was compacted with an initial water content of approximately $55 \%$ and on the east side with an initial water content of approx. $75 \%$. The compaction was performed by means of a heavy polygonal drum roller compactor (25 tons). With it a dry density of the dry and wet compacted material between $0.75 \mathrm{~g} / \mathrm{cm}^{3}$ and $0.85 \mathrm{~g} / \mathrm{cm}^{3}$ was achieved. After compacting the organic material the drainage mat was installed. For the noncompacted top layer, a clay with organic contents of similar properties was used.

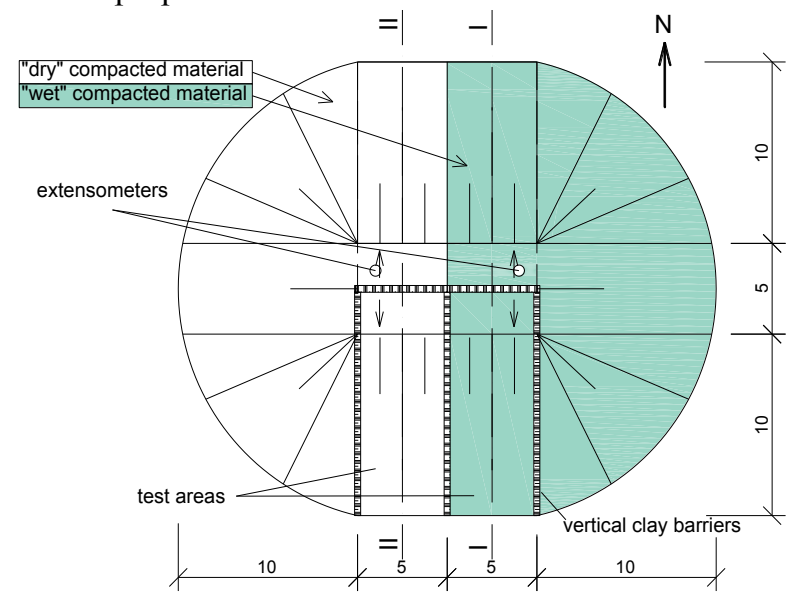

Figure 2. Plan View of the Test Embankment

On the south side of the fill, two areas of $5 \mathrm{~m}$ width and $12.5 \mathrm{~m}$ length were separated from the remaining part of the fill by vertical clay barriers of very low permeability (see figure 1). In these areas, twodimensional flow conditions can be assumed. For the analysis of the seepage extensive measuring systems were installed in these test areas. The leachate at the bottom of the embankment is collected by a drainage mat and an underlying geomembrane. A tube connected to the geomembrane discharges the water to a gauge well situated on the south side of the fill, where the leachate discharge is measured by electronic balances. The interflow in the drainage mat covering the compacted organic soil is collected at the bottom of the test areas and measured in the gauge in a like manner. The flow of water in the compacted organic soil is monitored by means of tensiometers and TDR-probes. The position of these sensors after compaction is shown in Figure 3.

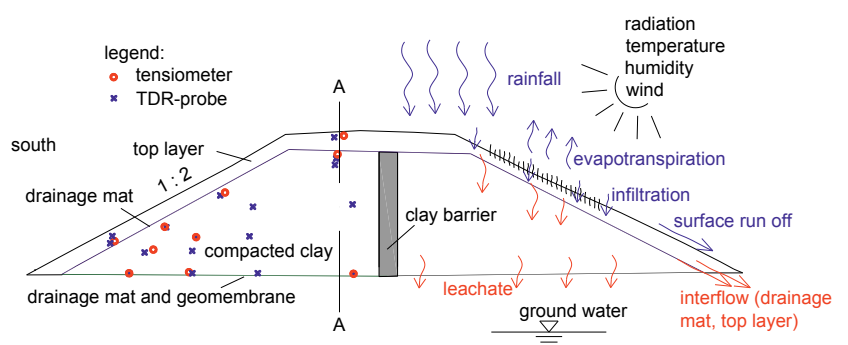

Figure 3. Cross section of the fill with the final arrangement of the tensiometers and TDR-probes (left section) and the description of the water balance (right section)

For the determination of the volumetric water content by means of the signals of the TDR-probes, a calibration of the TDR-probes had been performed.

For the simulation of the water balance of the fill the climatic conditions have to be known. The climate is measured by a meteorological station close to the fill. It consists of several sensors measuring the air temperature and humidity, the effective radiation, the wind velocity and direction as well as the amount of precipitation.

The vertical deformations of the fill are measured by means of four extensometers, installed in two boreholes; one in the wet and one in the dry compacted material (see Figure 2). The water balance of the fill is shown schematically in Figure 3.

\section{Results and analysis}

\subsection{Precipitation}

The precipitation recorded at the fill between November 2008 and June 2014 is shown in Figure 4. The precipitation pattern is typical for the south of Germany showing a maximum in the summer months. This is caused by the accumulating effect of the Alps that is particularly significant during the summer months. In total a precipitation of $4308 \mathrm{~mm}$ was measured, which leads to an average annual precipitation of $760 \mathrm{~mm}$. Especially the years 2013 and 2014 were slightly drier and the years 2010 and 2012 significantly wetter than the average. 


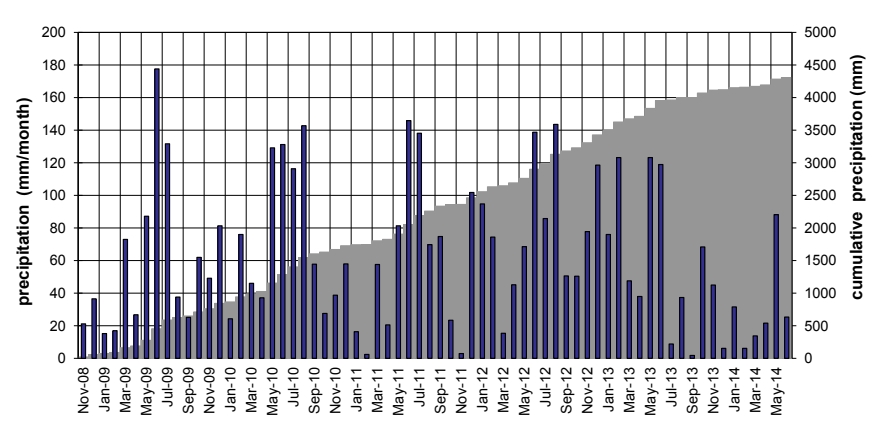

Figure 4. Measured precipitation at the fill

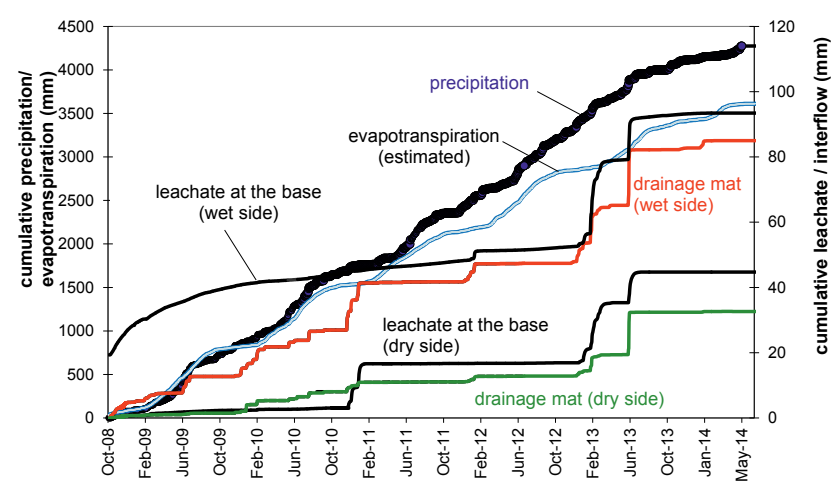

Figure 5. Cumulative water volumes of precipitation, evapotranspiration, drainage interflow and leachate for the wet and dry compacted clay

\subsection{Seepage and interflow}

Figure 5 shows the accumulated water volumes of precipitation, evapotranspiration, interflow in the drainage mat and leachate at the bottom of the wet and dry compacted material. For the wet side $93 \mathrm{~mm}$ were collected at the base of the test area in the entire observation period and $85 \mathrm{~mm}$ from the drainage mat placed above the compacted organic clay. In comparison to the total precipitation of $4308 \mathrm{~mm}$ these are very small fluxes (approx. $2 \%$ ). For the dry compacted clay even smaller fluxes for the leachate at the base $(45 \mathrm{~mm})$ as well as for the drainage mat (33 $\mathrm{mm})$ were recorded. This is caused by the low water content of the "dry" compacted material for which reason main part of the seepage water is retained by it. The small cumulative interflows collected from the drainage mats of the wet and dry side show that the top soil has a high water retention capacity and that evapotranspiration plays a significant role.

In detail the amount of leachate collected at the base of the wet and dry compacted soil is given in Figure 6. For the wet side comparatively large leachate arose directly after compaction in September 2008. Taking the measured pore water pressures into consideration, a consolidation process was initiated by the compaction of the wet clay. In some areas the water content of the wet compacted material was too high, so that excess pore water pressures were generated by the heavy compaction equipment. The consolidation phase is assumed to be widely completed at the end of April 2009. After April 2009 the leachate flow reduced further and took on an approximately constant value in January 2010. Thenceforth a mean leachate flux of approx. 0.3 $\mathrm{mm} / \mathrm{month}$ was measured at the base of the wet side except of the periods between November 2010 to February 2011, December 2011 to February 2012 and January 2013 to June 2013. High seepage of approx. 37 $\mathrm{mm}$ was measured especially between January 2013 and June 2013. This was caused by very high precipitation within these 6 months. Due to the comparatively dry climate conditions since August 2013 no significantly seepage was measured.

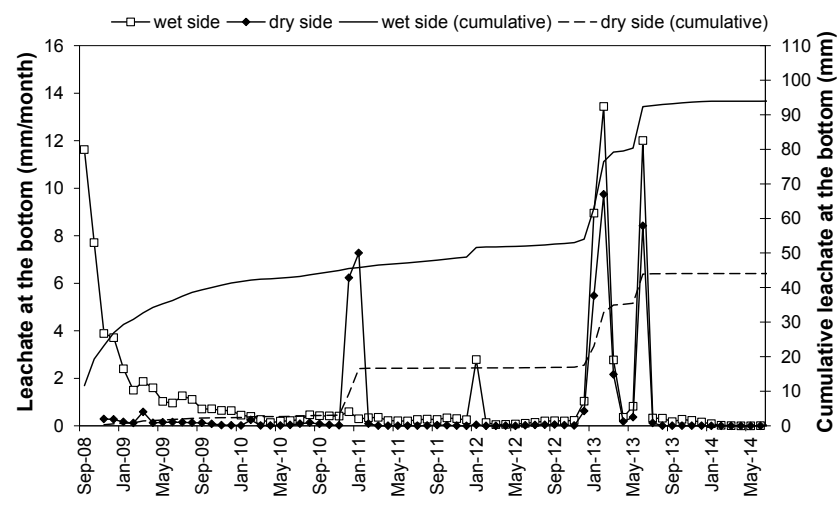

Figure 6. Leachate at the Base of the Embankment

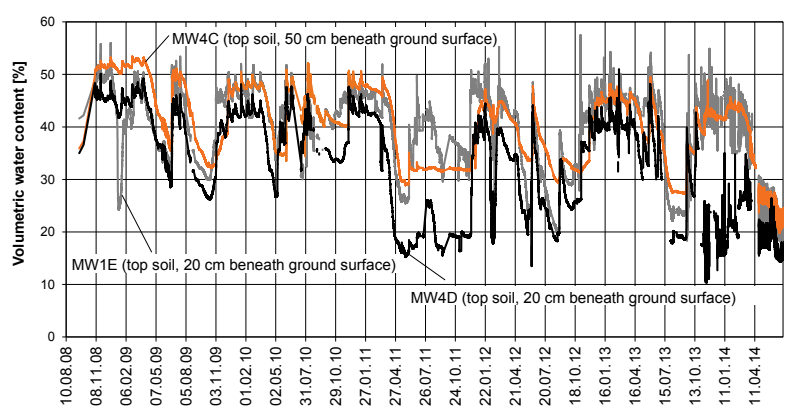

Figure 7. Volumetric Water Content in the Top Soil

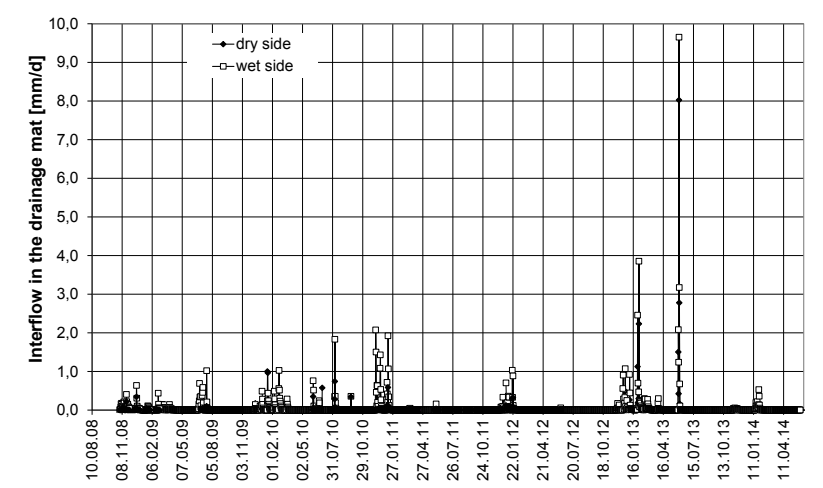

Figure 8. Interflow in the drainage mat

From the measurements of the TDR-probes located in the top soil it can be seen (Figure 7), that the interflow in the drainage mat (Figure 8) correlates with the time dependent variation of the water content in the top layer. An interflow in the drainage mat occurs only when the top soil is nearly saturated. This happens usually in winter, when no evapotranspiration takes place or in summer after a wet period with high precipitation (e.g. in 
summer 2013). As the wet compacted clay is almost saturated after compaction, less water is absorbed by the soil and a higher interflow in the drainage mat is noticeable in comparison to the dry compacted soil. However, similar to the dry side, an interflow in the drainage mat takes place only occasionally, when the top soil reaches water contents above the water content at field capacity and thus infiltrating water can not be retained.

\subsection{Evapotranspiration}

The potential evapotranspiration was determined by the Penman-Monteith equation as described by Allen et al. (1998) [3]. For the determination of the aerodynamic resistance a crop height of the grass vegetation of $15 \mathrm{~cm}$ was assumed. The leaf area index was estimated according to [3] at 3.6, with which a surface resistance of $56 \mathrm{~s} / \mathrm{m}$ was determined. Due to the inclination of the test fill and the resulting different net solar radiation on the inclined slopes, the potential evapotranspiration determined by Penman-Monteith had to be corrected. According to Golf [4] the evapotranspiration on the south facing slopes was increased by a factor of 2 for the winter half-year and a factor of 1.25 for the summer half-year. The potential evapotranspiration ETp describes the maximum evapotranspiration that is possible for saturated soils. The actual evapotranspiration depends on the water content of the top soil. For the determination of the actual evapotranspiration ETa the following equation of Disse [5] was used:

$$
E T_{a}=\frac{1-e^{-r \cdot \frac{\theta-\theta_{P W P}}{\theta_{F K}-\theta_{P W P}}}}{1-2 \cdot e^{-r}+e^{-r \cdot \frac{\theta-\theta_{P W P}}{\theta_{F K}-\theta_{P W P}}}} \cdot E T_{p}
$$

By means of this equation the actual evapotranspiration ETa can be determined from the potential evapotranspiration ETp considering the actual water content of the top soil $\theta$, the water content at field capacity $\theta_{\mathrm{FK}}$ and the water content at the permanent wilting point $\theta_{\text {PWP. }}$. The parameter $r$ depends on the vegetation and was taken to be $r=4$ according to [5]. The volumetric water content at the wilting point was determined from the soil-water retention curve of the top soil as the water content at a matric suction of $1500 \mathrm{kPa}$. For the determination of the volumetric water content at field capacity the volumetric water contents measured at the beginning of the growing seasons (see Figure 8) were analyzed. By doing so a value of 0.45 was taken. The actual volumetric water content $\theta$ was taken from field measurements. As the root depth of the grass vegetation was assumed to be larger than $20 \mathrm{~cm}$ only the measurements of the sensor MW4C located approx. 50 $\mathrm{cm}$ beneath the ground surface (see Figure 8) were used, allowing the determination of the actual evapotranspiration given in figure 9. According to the climatic conditions in the summer half-years a significant evapotranspiration take place while in the winter halfyears the evapotranspiration is comparatively small. For the entire observation period between November 2008 and June 2014 an evapotranspiration of $3605 \mathrm{~mm}$ was determined (see figure 9). This means, that approx. $84 \%$ of the precipitation removed from the ground surface and the top soil by evaporation and transpiration. This explains the small seepage fluxes recorded at the drainage mat of the wet side.

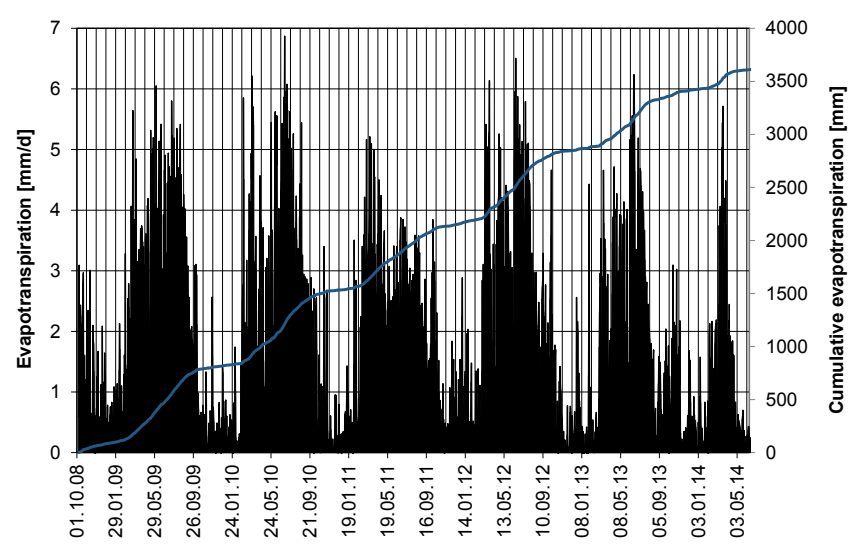

Figure 9. Estimated Evapotranspiration

\subsection{Storage}

For the wet side it can be assumed that for the period between 2008 and 2014 no relevant storage has occurred as the material was almost saturated after compaction. This is confirmed by the measurements of the water content sensor at the base of the fill which show no significant changes over the considered time period (see Figure 10).

In contrast, the dry compacted organic clay retains a significant part of the infiltrating water and thus the seepage at the base of the dry side and the interflow from the drainage mat of the dry side is only half of that collected from the wet side. From Figure 11 it can be seen how the water content of the dry compacted material at the base of the fill increased with time. The initial volumetric water content was between $40 \%$ and $50 \%$. In summer 2014 the water content has reached values between $48 \%$ and $60 \%$.

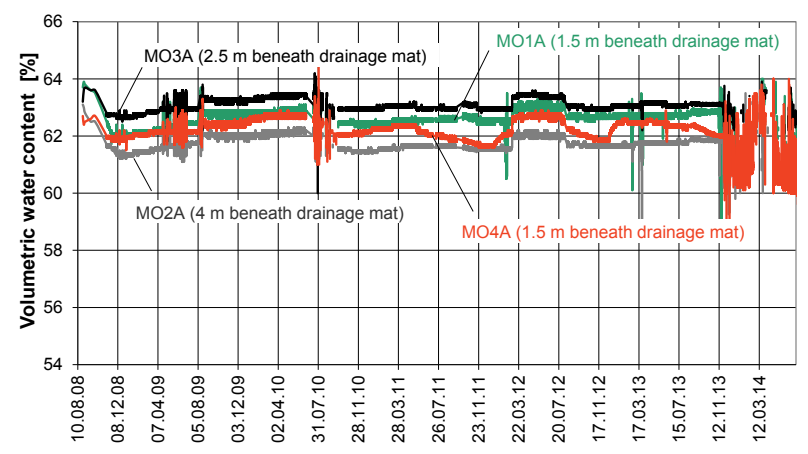

Figure 10. Volumetric water contents at the base of the wet side 


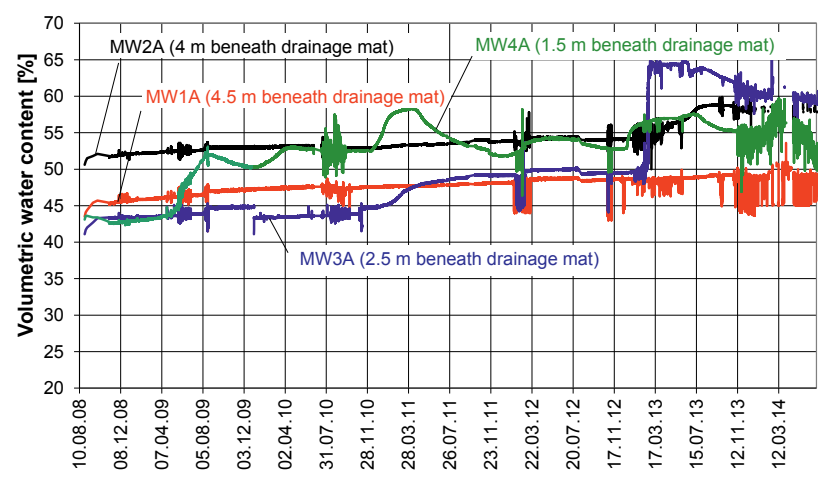

Figure 11. Volumetric water contents at the base of the dry side

\subsection{Surface run off}

According to the water balance equation the precipitation (N) must be equal to the sum of evapotranspiration (ET), surface run off (SR), seepage flow (seepage at the base and interflow - S) and storage (W):

$$
N=E T+S R+S+W
$$

As described in chapter 4.4 for the wet compacted organic clay the storage can be neglected. Thus the surface run off, which is not measured directly, can be calculated from the precipitation, the evapotranspiration and the seepage flow as follows:

$$
S R=N-E T-S
$$

According to the cumulative fluxes shown in Figure 5 the accumulated surface run off between 2008 and 2014 is $503 \mathrm{~mm}$. As the same material was used for the top layer of the wet and the dry side, for the dry side a similar surface run off is expected.

\section{Conclusions}

For the detailed investigation of seepage quantities through a slightly contaminated organic clay a $5 \mathrm{~m}$ high, $30 \mathrm{~m}$ long and $25 \mathrm{~m}$ wide test fill was constructed. In view of the low permeability of the soil after compaction it was covered only by a drainage mat and a top soil without an additional sealing liner. As the hydraulic behavior depends strongly on the compaction water content, the test fill was divided in two parts. In the west side the soil was compacted at an initial water content dry of Proctor Optimum and in the east side at a water content wet of Proctor Optimum. For the measurement of the water balance of the fill including seepage flow through the compacted organic soil extensive measuring devices were installed. From the measurements the following results were obtained:

The seepage collected at the base of the wet compacted clay in the period between November 2008 and June 2014 amounts to less than $2 \%$ of the precipitation. Also the interflow in the drainage mat above the wet compacted clay is small (2\% of precipitation).

The seepage collected at the base of the dry compacted clay between November 2008 and June 2014 is $1 \%$ of precipitation and so even smaller than that of the wet compacted clay. Also the interflow in the drainage mat above the dry compacted clay is small as significant part of the seepage water is retained by the dry compacted clay. This means that a saturation process takes place and that the seepage at the base of the dry compacted clay could increase once the retention capacity of the soil is reached.

Evapotranspiration plays an important role for the water balance of the test fill. Due to the high retention capacity of the soil and the underlying drainage mat which acts as a capillary break, the evapotranspiration reaches approx. $84 \%$ of the precipitation.

In comparison to measurements obtained for landfill covers in humid climates ([6], [7], [8]) the percolation of the top layer is very low and the evapotranspiration is very high. This is caused by the high organic content of the top layer, that results in a high water retention capacity, the high inclination of the test fill slope $\left(26,6^{\circ}\right)$ and the low permeability of the compacted organic clay.

\section{References}

1. E. Birle, M. Boso, D. Heyer. $5^{\text {th }}$ Int. Conf. on Unsat. Soils. Vol. II, pp. 1299-1304 (2004)

2. E. Birle, D. Heyer: GeoCongress 2012, Oakland, (2012)

3. R. G. Allen, L. S. Pereira, D. Raes, M. Smith. Computing crop water requirements - FAO irrigation and drainage paper 56, (1998)

http://www.fao.org/docrep/X0490E/x0490e00.htm

4. W. Golf. Ermittlung der Wasserressourcen im Mittelgebirge, Wasserwirtschaft und Wassertechnik 31, pp. 93-95 (1981), cited in DVWK Merkblatt 238/1996: Ermittlung der Verdunstung von Landund Wasserflächen [Determination of Evaporation on Land- and Water Surfaces]

5. M. Disse M. (1999). Physics and Chemistry of the Earth, Vol. 24, No. 4, pp. 325-330, Elsevier Science Ltd. (1999)

6. W. H. Albright, C. H. Benson, G. W. Gee, A. C. Roesler, T. Abichou, P. Apiwantragoon, B. F. Lyles, S. A. Rock. J. Environ. Qual. Vol. 33, pp. $2317-$ 2332 (2004)

7. W. U. Henken-Mellies. Höxteraner Berichte zu angewandten Umweltwissenschaften; Vol. 03, pp. 117-126 (2002)

8. S. Melchior, K. Berger, B. Vielhaber, G. Miehlich. Höxteraner Berichte $\mathrm{zu}$ angewandten Umweltwissenschaften; Vol. 03, pp. 57-74 (2002) 